\title{
Focusing on the "Public" in Public Relations: The Importance of Person-Centered Messages (PCMs) in Crisis Communication on Twitter
}

\section{Soo Kwang Oh${ }^{1}$, Kyung-Hyan Yoo ${ }^{2}$, and Jennifer Owlett ${ }^{2}$}

1. Seaver College, Pepperdine University, Malibu, CA, USA

2. Department of Communication, William Paterson University, Wayne, NJ, USA

\begin{abstract}
Based on the theoretical frameworks of situational crisis communication theory (SCCT) and person-centered messages (PCMs), this interdisciplinary study conducted a $2 \times 3$ experiment to examine the role of PCMs in crisis management on social media. Our findings suggest that crisis type (victim, preventable) has an effect on people's perceptions/reactions toward an organization and that PCM levels (low, medium, and high person-centered messages) in crisis communication on social media influence organizational reputation and participants' intention to post negative feedback about the organization in crisis. We suggest that when organizations are responding to crisis online, they provide additional attention to the interpersonal dynamics of those interactions. Theoretical and practical implications are discussed.
\end{abstract}

KEYWORDS: situational crisis communication theory, person-centered messages, social media, crisis communication

Within the past several years, multiple airlines have experienced major crisis events. For example, on April 7, 2017, Dr. David Dao boarded a United flight but was dragged through the aisles when he refused to voluntarily give up his seat due to overbooking (Goldstein, 2017). While Dr. David Dao's experience is notable, it unfortunately did not occur in isolation as a growing number of

CONTACT Soo Kwang Oh • E-mail: klive.oh@pepperdine.edu - Seaver College • Pepperdine University • 24255 Pacific Coast Highway • Malibu, CA 90263 USA 
public relations $(\mathrm{PR})$ crises are occurring within the transportation industry. In some instances, passengers or their canine companions died during the flight (Matousek, 2018). In other examples, passengers experienced confrontations with flight crew regarding their professional medical credentials (Hauser, 2018) or even if a stroller could be brought onboard (Rosenberg, 2017). Each issue presents a unique crisis but requires PR practitioners to craft an appropriate response to the concern.

PR practitioners have a variety of choices when responding to crises; in today's digital world, crisis usually breaks on social media first and it is often necessary to respond quickly on social media before making official organizational announcements. While a timely response is critical in crisis communication, message quality is also important since it can influence the attitudes and behaviors of the public. This is especially true for social media messages, which can be easily misinterpreted and then widely shared (Jong $\&$ Dückers, 2016). The service sector is particularly more vulnerable to potential crisis issues because of the nature of the industry (Smith, 2005) - which includes highly active stakeholders, intangible service quality, and increased consumer expectations.

Unfortunately, little work has been completed that examines how crisis message quality can influence post-crisis outcomes (e.g., reputation and consumer intentions) within the context of social media. Therefore, the goal of this study is to investigate how the quality of social media messages during a crisis influences the publics' attitudes. This study focuses on the service industry, where consumers are often an integral part of the service system and help to shape the organization's reputation (Dotchin \& Oakland, 1994; Edvardsson, 1992). This arguably makes the field more prone to social media-based complaints from stakeholders (consumers) and the customers' evaluations could severely affect the service industry. Recently, several airlines have encountered crises caused by the customers' tweets and the strategic use of Twitter has become crucial in responding to crises (Schultz et al., 2014; Zhao et al., 2020). Moreover, publics often show an active presence on Twitter during crises to fulfill their information needs (Veil et al., 
2011; Zhao et al., 2019). Therefore, this study aims to examine the airline companies' Twitter responses in crises.

To do so, this study employed situational crisis communication theory (Coombs, 2007), with attention to message quality through person-centered messages (PCMs; Burleson, 1987). Person-centered messages have previously focused on interpersonal communication contexts, but have also been applied to understanding how publics respond to crisis messages. We begin by providing a review of situational crisis communication theory and person-centered messages before turning to our study.

\section{Literature Review}

\section{Crisis Communication: Situational Crisis} Communication Theory

Situational crisis communication theory (SCCT; Coombs, 2007) is a commonly used theoretical framework in crisis communication research. It provides a way to better understand the organization's crisis response in light of reputation. SCCT posits that an organization's reputation can be protected during a crisis if appropriate communication response strategies are selected (Coombs, 2007; Kiambi \& Shafer, 2016). To do so, an organization should identify the crisis type and determine the initial crisis responsibility. According to SCCT, crisis types can be grouped into three clusters (victim, accidental, and preventable) based on levels of crisis responsibility (Coombs, 2007, 2011). In the victim cluster, the organization's crisis responsibility is low because stakeholders view the organization as a victim. Crises in the accidental cluster occur when crisis-causing events are viewed as unintentional or uncontrollable. Stakeholders do not expect the organization to take high responsibility for events in these settings. The preventable cluster contains strong attributions of crisis responsibility, as the event is deemed to be something under the organization's control and could have been avoided with proper measures (see Table 1). 
TABLE 1 Crisis Types

\begin{tabular}{|l|l|}
\hline Crisis Clusters & Crisis Types \\
\hline Victim cluster & $\begin{array}{l}\text { Natural disaster } \\
\text { Rumor } \\
\text { Workplace violence } \\
\text { Product tampering/Malevolence }\end{array}$ \\
\hline Accidental cluster & $\begin{array}{l}\text { Challenges } \\
\text { Technical-error accidents } \\
\text { Technical-error product harm }\end{array}$ \\
\hline Preventable cluster & $\begin{array}{l}\text { Human-error accidents } \\
\text { Human-error product harm } \\
\text { Organizational misdeed with no injuries } \\
\text { Organizational misdeed management misconduct } \\
\text { Organizational misdeed with injuries }\end{array}$ \\
\hline Source: Coombs (2007). \\
\hline
\end{tabular}

The organization should then select suitable crisis response strategies that correspond to the appropriate crisis clusters or levels of responsibility attribution to alleviate negative public reactions (Coombs, 2007). Previous crisis history and relationship reputation should also be considered. As threats to an organization's reputation increase, more accommodative crisis response strategies should result-these strategies demonstrate greater concern for victims (Coombs, 2007). Stakeholders are also more likely to perceive the organization is taking greater attribution and responsibility when such strategies are used (Coombs \& Holladay, 2004, 2005). Taking responsibility is especially important for preventable crisis categories because this type often generates strong emotions (increased anger and decreased sympathy) about the organization (Coombs \& Holladay, 2005). Negative emotions can cause stakeholders to engage in expressing their negative attitudinal and behavioral responses publicly, which can also affect an organization's reputation (Coombs \& Holladay, 2004).

With the growing importance of organizational social media use for crisis communication, several recent studies have tested SCCT in the social media context. For example, Coombs and Holladay (2012a) analyzed the effectiveness of an apology strategy for an online crisis and confirmed the effectiveness in managing the 
online crisis as prescribed in SCCT. Similarly, Brummette and Fussell Sisco (2015) applied SCCT for the case studies of three organizations' social media crises and found that the theory is useful to identify effective versus non-effective crisis response strategies to social media crises. More recently De Waele et al. (2020) examined how social media publics reacted to situational and renewing organizational responses across six crises based on SCCT and discourse of renewal (DOR) theory. Their findings confirmed that showing sympathy in crisis responses is effective across all six crisis situations, which are consistent with the accumulating literature that supported SCCT. However, the results regarding the effects of the rebuild and diminish strategies were inconsistent with what SCCT proposed, which calls for more studies to test SCCT in the social media context. Therefore, this study proposes the following hypotheses based on SCCT to further test the theory with regard to social media.

H1: Crisis type (victim, preventable) will have an effect on people's perceptions/reactions toward an organization.

H1a: Anger/negative emotions toward the organization will be lower for the victim crisis than for the preventable crisis.

H1b: Perceived reputation of the organization will be more favorable for the victim crisis than for the preventable crisis.

H1c: Consumer intentions regarding the organization will be more favorable for the victim crisis than for the preventable crisis.

\section{Person-Centered Messages}

While understanding levels of perceived responsibility is important, SCCT also points to the importance of crisis response. One way in which this can be implemented is through crafting messages that are tailored to the crisis event and relevant publics. Unfortunately, few practical guidelines currently exist for crisis communication practitioners when responding to crisis events that unfold online (Rains et al., 2016). Practitioners may gain insight for these messages by turning to the supportive communication literature (e.g., Jones \& Bodie, 2014) that examines comforting communication. While SCCT suggests that attention be provided to crisis types and 
responsibility, more competent crisis responses can be developed if consideration is given to the interpersonal dynamics of those interactions. To do so, emphasis should be placed on examining person-centered messages (Burleson, 1982; 1987). Integrating person-centered messages (PCMs) with SCCT allows crisis messages to respond to the multidimensional concerns that crisis entails.

Person-centered messages (PCMs) "reflect an awareness of and adaptation to the subjective, affective, and relational aspects of communicative contexts" (Burleson, 1987, p. 305). PCMs are part of constructivism (Delia et al., 1982), which is a theory of communicative competence (see, e.g., Bodie \& Jones, 2016). Communicative competence refers to the "ability to generate and process messages in ways that enable people to accomplish their social goals appropriately and effectively" (Bodie \& Jones, 2016, p. 2). Person-centered messages exist at nine distinct levels, with higher levels representing increased communicative competence (Burleson, 2008). These nine levels can be collapsed into three larger areas (Burleson, 1994). Low person-centered messages (LPCs) often condemn other's feelings (LPC-level 1), challenge the legitimacy of other's feelings or actions that follow these feelings (LPC-level 2), or ignore the other's feelings (LPC-level 3). In comparison, medium person-centered messages (MPCs) attempt to reframe situations in a positive way (MPC-level 4), acknowledge feelings but do not assist the other in understanding those feelings or coping with them (MPC-level 5), or provide non-feeling-centered explanations that intend to reduce the other's emotional distress (MPC-level 6). Finally, highly person-centered messages (HPCs) recognize the other person's emotional reaction but do not provide elaboration for those feelings ( $\mathrm{HPC}-$ level 7), provide an elaborated acknowledgment and explanation of those feelings (HPClevel 8), or help the other to gain perspective on one's own feelings and attempts to link the feelings in relation to a broader context (HPC-level 9; High \& Dillard, 2012). The use of person-centered messages has been linked to a variety of positive outcomes. Specifically, person-centered messages have been found to be especially helpful within the comforting communication area. For example, Jones (2004) indicated that when individuals shared a mildly 
upsetting event with another person, they not only felt better but also rated the support provider as more supportive and caring when person-centered messages were implemented. Validation of one's behavioral intention is also an important element within person-centered support messages. As B. Feng and colleagues (2016) note, when seeking support for a behavioral intention, such as changing one's job, support seekers might solely be looking for validation from a support provider. Those support providers that use more person-centered messages are more likely to be viewed as effective (Eichhorn, 2008; B. Feng et al., 2016). The implications of using more highly person-centered messages become further exacerbated when one examines the use of support messages in online settings. For example, Rains et al. (2016) completed a comprehensive analysis of the extant literature on the relationship between computer-mediated communication (CMC) and social support. Their summary indicates that social support is frequently accessed and provided in online settings and for various reasons (i.e., perceived stigma, accessibility, and control). Interestingly, the literature notes that individuals using CMC to gain support have stronger motivations to receive it in comparison to those who seek support face-to-face. Furthermore, individuals who seek support through CMC also report larger changes in worry and uncertainty discrepancy, when compared to those in face-to-face settings (Rains et al., 2016). Several studies (Abendschein, 2020; Pan et al., 2020; Wright et al., 2012) demonstrate the ability of CMC to connect individuals for health-related information, but CMC can be used for support purposes in other contexts, as well.

With this in mind, it is especially important to consider the role that person-centered messages can play in CMC provided support messages.

\section{Social Media, Crisis Communication, and PCMs}

The rise of social media has brought along with it an audiencecentric communication approach, due to the instantaneous and interactive nature of emerging platforms. Messages travel faster and farther with enhanced connectivity and access (Diddi \& Lundy, 2017; Killian \& McManus, 2015). Key publics are able 
to receive, evaluate, and engage with messages at the touch of a button, making it more important than ever for practitioners to identify key publics, gauge public opinions, and adopt appropriate message strategies (Jiang et al., 2016). Moreover, social media users can directly respond to organizations, making two-way dialogue a staple in strategic communication (Grunig, 2009).

Social media is also the hotbed of sharing ideas, which makes word-of-mouth (WOM) a key topic to consider for crisis communication. Social media users can create huge waves of outrage within just a few hours, which Pfeffer and colleagues (2014) call "online firestorms" (p. 117). In fact, Pace and colleagues (2017) found that social media audiences react differently to a brand crisis when compared to their mass media counterparts. Those with higher engagement on social media not only had more negative attitudes toward the brand, but also had intensified intentions for sharing those negative views via WOM.

This calls for the importance of PCMs in crisis communication for several reasons. First, effective crisis management requires practitioners to pay attention to the attitudes and demands of affected publics. Consequently, creating messages tailored to stakeholders' concerns is a primary goal. In message creation, PCMs ought to be emphasized, especially in cases where support or consolation is expected or required (Jones, 2004). Relevant studies have confirmed the positive effect of this, especially regarding publics' empathy toward organizations. Schoofs and colleagues (2019) found that in crisis situations, proper apology from the organization leads to empathy among stakeholders and increases reputation recovery (unlike denial). An experiment from J. Kim \& Jin (2016) observed that publics' perceived involvement in the issue results in varied levels of emotions (e.g., anger, empathy) toward the organization, highlighting the importance of appropriate response strategies. This works the other way around as wellanother study found that when CEOs express emotions in crisis response, publics feel empathy toward the CEO, which results in positive attitudes toward the organization (De Waele et al., 2020).

Second, the present study examines crisis situations in the service industry. The service encounter, the moment when the company's employees meet and interact with customers, has occurred 
increasingly online. In the online context, customers expect two-way dialogue with the company (Grunig, 2009) and more customer-centric communication, which are often emphasized in PCM to enhance communicative competence (Burleson, 2008). Czepiel and colleagues (1985) discuss how customers perceive service encounters are critical factors in how service quality is evaluated. If the service provider fails to meet the customer's service expectations, the customer can easily challenge the organization on social media, while others can view these challenges as well. This heightened visibility raises new strategic and tactical concerns for crisis managers (Coombs \& Holladay, 2012b), which consequently shapes an organization's reputation (Edvardsson, 1992). This, in turn, increases the potential for an organizational crisis because of the variable and changing nature of consumers' perceptions (Smith, 2005).

Finally, PCMs-rooted in interpersonal communicationshould be considered in social media communication due to its characteristics as personal media, where dialogue often resembles that of interpersonal interactions (Lee et al., 2016).

Although there is considerable research attention in the crisis management area, previous research has yet to address the personcentered message quality approach with regard to crisis communication on social media. By the same token, studies suggest that organizations still need guidelines when responding via social media (Eriksson, 2012; Veil et al., 2011).

H2: PCM levels (LPC, MPC, HPC) in social media crisis communication will have an effect on people's perception/reactions regarding an organization.

H2a: Higher PCM levels in social media crisis communication will result in lower anger/negative emotions toward the organization.

H2b: Higher PCM levels in social media crisis communication will result in a more favorable perceived reputation of the organization.

H2c: Higher PCM levels in social media crisis communication will result in more favorable consumer intentions toward the organization. 
RQ: Are there any interaction effects between the crisis type and PCM levels in social media crisis responses on people's perception/reaction regarding an organization?

The authors posit that through an interdisciplinary approach that integrates applied communication (SCCT) and interpersonal communication (PCMs), this study provides guidance for how organizations can respond to crisis through social media. Furthermore, this study will provide a better understanding about the effects of PCM levels in different crisis situations on organizational reputation and key publics' attitudinal and behavioral responses.

\section{Method}

\section{Design and Stimuli}

This study employed a 2 (crisis type: victim, preventable) $\times 3$ (PCM level: low, medium, high) between-within mixed factorial experimental design (Gliner et al., 2009). The Participants ( $n=133$ ) were randomly assigned to one of two experimental groups (between-subjects, crisis type), and then each participant in each group was exposed to three stimulus messages (within-subjects, PCM level) in random order. The within-subjects component of this experimental design was deemed appropriate to control for individual differences in perceiving the messages, therefore "greatly increasing the sensitivity of the measurements" (Lyon \& Cameron, 2004, p. 222). That is, this design accommodates naturally occurring differences between individuals in the social media setting. Moreover, to address concerns about withinsubjects designs being too transparent about the research hypothesis, Lambdin and Shaffer (2009) found that participants were unable to identify the hypotheses and inaccuracies in their predictions of the transparency of a within-subjects design. This design has also proven to be effective in measuring crisis communication messages from organizations (Hong \& Len-Riós, 2015; Jin, 2009).

For the experiment, we manipulated crisis type by selecting one crisis from two clusters (victim and preventable) (Coombs, 2007; Coombs \& Holladay, 2002, 2009). The two crisis clusters were selected to represent each end of the crisis responsibility 
spectrum-in the victim type, the public tends to attribute minimal crisis responsibility to the organization experiencing the crisis, and the preventable type generates strongest attributions of crisis responsibility toward the organization (Coombs, 2007). This was adequate for differing the crisis example scenarios sufficiently for the purpose of this study. In a study comparing base crisis response with reputation management crisis response strategies, Kim and Sung (2014) also employed the two crisis clusters and found significant differences on how participants evaluated the clusters.

Among crises identified in each type, we then selected crisis examples based on realistic and commonly occurring airline issues. From the victim cluster, we selected natural disaster. From the preventable cluster, we chose organizational misdeed with no injuries. A fictitious airline was used to avoid potential confounding effects from pre-existing knowledge.

Furthermore, three tweets were generated for each crisis type to reflect three PCM levels (LPCs, MPCs, and HPCs). Each message was created specifically for this study, with the purpose of displaying varying levels of person-centeredness within each scenario. The level of person-centeredness in each tweet message was based on Burleson's (1982) 9-category typology in conjunction with PCM strategies suggested by Sellnow et al. (2015). Key elements were mention of others (acknowledging the recipient, in this case, the customer), sympathy (displaying sympathy for the problem-e.g., "we understand"), responsibility (taking responsibility), apology and support/solutions (offering support and/or solutions). In our study, LPC (low person-centered) messages simply described the facts of the issue with a representative customer service phone number. MPC (medium person-centered) messages offered limited support or sympathy (but not both) and provided an additional method for communication (e.g., encouraging the individual to send a direct message). HPC (high person-centered) messages displayed all the four elements and contained a personal and detailed message that addressed that specific customer and his/her problems. These tweet messages were pre-tested by two interpersonal communication scholars, who were presented with Burleson's (1982) 9-category typology for person-centered 
messages and the sample airline messages for review. These experts were asked to provide feedback about the included sample tweets with specific attention to message fit regarding the intended PCM categories (LPC, MPC, HPC). Following expert feedback and further discussion, we refined the messages until they confirmed the tweets corresponded to different levels of person-centeredness. In this study, we focused strictly on Twitter given its conversational nature and instantaneous response characteristics of users and corporations. We therefore deemed it best suited to explore crisis message effectiveness on social media. See Figure 1 for an example of the tweet messages for the PCM levels.

\section{Participants and Procedure}

Participants ( $n=133$ ) were recruited from undergraduate communication courses at two U.S. universities with the option of receiving extra credit. More females (65\%) than males (35\%) participated in the study. The majority $(83.5 \%)$ of participants were in the 18-24 age group, followed by $25-30$ (12\%), 31-40 (2.3\%), and $41-50(2.3 \%)$. In terms of airline usage frequency, about half $(48.9 \%)$ of participants reported that they used air transportation one to four times in the last 2 years from when the data was collected. Seventy-one percent of participants had Twitter accounts.

\section{FIGURE 1 Tweet Message Examples for Each Crisis Type Cluster (Top: Preventable, Bottom: Victim) and PCM Level (Left: HPC, Middle: MPC, Right: LPC)}

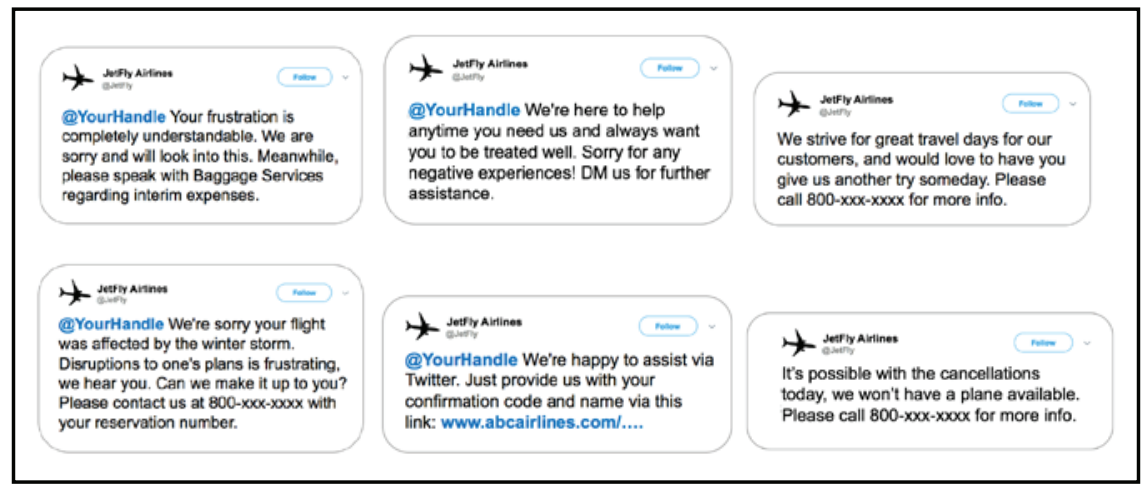


Among those, $58.1 \%$ said they always or frequently use their Twitter accounts while about $22 \%$ of users visited the platforms sometimes or occasionally.

The survey link directed each participant to one of the two crisis types. At the beginning, participants read the scenario for their assigned crisis type, followed by questions regarding the airline's responsibility, amount of control, and responsibility. Afterward, the participant was shown three tweets, in random order, that represented each PCM level. Each tweet was followed by questions regarding anger/negative emotions, corporate reputation, and behavioral intentions. Data was collected between December 2017 and April 2018.

\section{Measures}

Consumer intentions were measured by adopting Coombs and Holladay's (2008) negative WOM intention item: "I would encourage friends or relatives to NOT travel with this airline," assessed on a 7-point scale ranging from "strongly disagree" to "strongly agree."

Anger/Negative Emotions were assessed by adopting Jorgensen's (1996) measure of anger toward the company. This study used a 7-point scale ("not at all annoyed" to "very annoyed"). Using a single-item measure was deemed appropriate, given Bergkvist and Rossiter's (2007) findings that single-item measures for concrete constructs (e.g., consumer reactions, attitudes) in marketing/ brand research demonstrated equally high predictive validity as multiple-item measures.

Corporate reputation was assessed using 11 items, adapted from previous studies regarding organizational reputation (Coombs \& Holladay, 2002; Ponzi et al., 2011) and person-centeredness (Sellnow et al., 2015). All items were measured on a 7-point Likert scale. Factor analyses were conducted to evaluate the dimensionality of the scale while the scale reliability was measured using Cronbach's coefficient alpha. Based on the factor loadings and alpha scores, four items were removed which resulted in a seven-item corporate reputation scale. The seven items (see Table 2) demonstrate high internal consistency for measuring airlines' reputation 


\section{TABLE 2 Corporate Reputation Measurement Items}

The organization is concerned with the well-being of its publics

Under most circumstances, I would be likely to believe what the organization says

The airline is a company I have a good feeling about

The airline is a company that I trust

The airline is a company that I admire and respect

The airline has a good overall reputation

This airline cares about its customers

at low, medium, and high PCM levels, respectively $(\alpha=0.93,0.92$, and 0.94$)$.

\section{Manipulation Checks}

Crisis type was manipulated by providing participants with one of two hypothetical scenarios for potential crisis situations. After reviewing the scenario, participants were asked to determine the organization (airline)'s responsibility for that specific crisis. The following statement was presented: "The blame for the crisis lies in the circumstances, not the organization." Then they received three PCM levels of responses (tweets) from the airline and were asked to evaluate each response using the following statement: "The airline cares about its customers." Participants rated their agreement for these statements on a 7-point Likert scale from 1 (strongly disagree) to 7 (strongly agree). The manipulation check results suggest that the stimuli were effective. The participants assigned to the preventable crisis type assessed the airline's responsibility for the crisis is significantly higher $(M=4.8, S D=1.68)$ than victim type $(M=2.9, S D=2.1), t(126)=-5.78, p<.001$. In addition, participants reported that the airline cared more about customers when the airline responded with highly person-centered messages $(M=$ 5.36 for victim; $M=5.0$ for preventable) in comparison to either 
the MPC ( $M=4.61$ for victim; $M=4.67$ for Preventable) or LPC messages $(M=3.51$ for victim; $M=3.39$ for preventable), $F$ (1.94, 253.46) $=64.01, p<.001$.

\section{Results}

\section{Influence of Crisis Type and PCM Levels of Crisis Responses on Emotion, Corporate Reputation, and WOM Intentions}

To assess the main effects of crisis type, PCM levels of crisis responses, and any possible interactions on the participants' negative emotions, perceived corporate reputation, and negative WOM intention, a series of mixed between-within subjects ANOVAs were conducted.

\section{Negative Emotions}

We first analyzed the influence of crisis type and PCM levels of crisis responses on negative emotions toward the organization. Findings suggest no significant differences exist for participants' negative emotions toward the organization between the victim and preventable crisis types $(F(1,131)=.13, p=.72)$. Mean scores indicate that negative feelings toward the organization are similar for both crisis types ( $M=3.64$ for victim; $M=3.57$ for preventable). Thus, H1a was not supported. However, there was a significant main effect of crisis responses' PCM levels on negative emotions toward the organization $(F(1.93,252.16)=67.44, p=.00)$. A large effect size (.34) was located using eta-squared $\left(\eta^{2}\right)$ (Cohen, 1988). Mean scores suggest that people's negative emotions decreased as the person-centeredness of crisis responses increased (See Table 3; Figure 2). Therefore, H2a was supported. There was no significant interaction between the crisis type and the PCM levels of crisis responses in terms of people's negative emotions toward the organization $(F(1.93,252.16)=1.79, p=.17)$. 
FIGURE 2 Negative Emotions for Three Levels of Person-Centered Messages in the Victim and Preventable Crisis Types

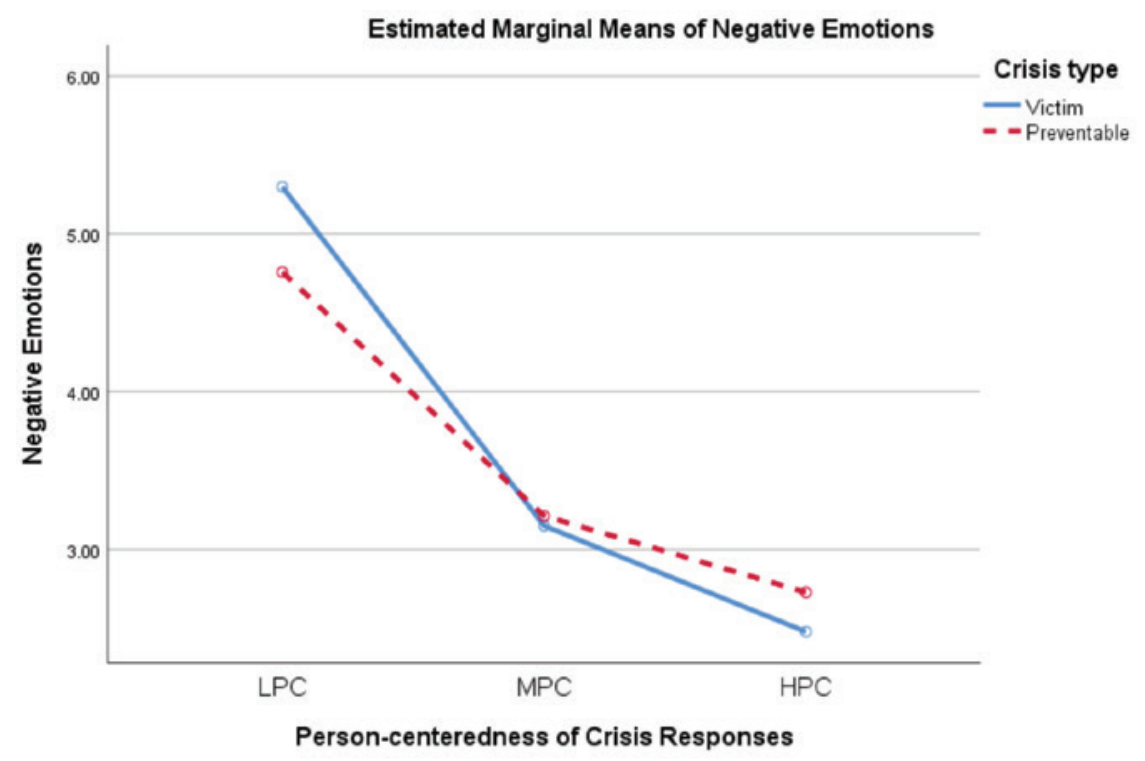

\section{Corporate Reputation}

The effects of crisis type and PCM on participants' perceived organizational reputation were also tested. A non-significant main effect of crisis type on corporate reputation $(F(1,131)=1.52$, $p=.22$ ) was found. This suggests that participants evaluated airlines' corporate reputation similarly for both victim and preventable situations ( $M=4.39$ for victim; $M=4.21$ for preventable). Consequently, $\mathrm{H} 1 \mathrm{~b}$ was not supported. However, there was a significant main effect of PCM levels on corporate reputation $(F(2,262)=68.98, p=.00)$. The eta-squared $\left(\eta^{2}\right)$ was .35 , a large effect (Cohen, 1988). As presented in Table 3 and Figure 3, more favorable perceived organizational reputation scores were reported with higher PCM levels. Therefore, $\mathrm{H}_{2} \mathrm{~b}$ was supported. There was no significant interaction between the crisis type and the PCM levels of crisis responses in terms of perceived corporate reputation $(F(2,262)=.33, p=.72)$. 
TABLE 3 Mean Levels of Negative Emotions, Corporate Reputation, and Negative WOM Intention by PCM Levels of Crisis Messages across Two Crisis Types

\begin{tabular}{|c|c|c|c|c|c|}
\hline \multirow{3}{*}{$\begin{array}{l}\text { People's } \\
\text { Perceptions/ } \\
\text { Reactions }\end{array}$} & \multirow[b]{3}{*}{ Crisis Types } & & \multicolumn{3}{|c|}{ PCM Levels of Crisis Messages } \\
\hline & & & LPC & MPC & HPC \\
\hline & & $N$ & $M(S D)$ & $M(S D)$ & $M(S D)$ \\
\hline \multirow{2}{*}{$\begin{array}{l}\text { Anger/Negative } \\
\text { Emotions }\end{array}$} & Victim & 67 & $5.30(1.94)$ & $3.15(1.95)$ & $2.48(1.91)$ \\
\hline & Preventable & 66 & $4.76(2.18)$ & $3.21(1.76)$ & $2.73(1.63)$ \\
\hline \multirow{2}{*}{$\begin{array}{l}\text { Corporate } \\
\text { Reputation }\end{array}$} & Victim & 67 & $3.59(1.30)$ & $4.46(1.08)$ & $5.10(1.15)$ \\
\hline & Preventable & 66 & $3.44(1.28)$ & $4.38(1.08)$ & $4.82(1.04)$ \\
\hline \multirow{2}{*}{$\begin{array}{l}\text { Negative WOM } \\
\text { Intention }\end{array}$} & Victim & 67 & $3.78(1.78)$ & $2.79(1.70)$ & $2.30(1.37)$ \\
\hline & Preventable & 66 & $4.17(1.79)$ & $3.56(1.73)$ & $3.05(1.72)$ \\
\hline
\end{tabular}

FIGURE 3 Corporate Reputation for Three Levels of Person-Centered Messages in the Victim and Preventable Crisis Types

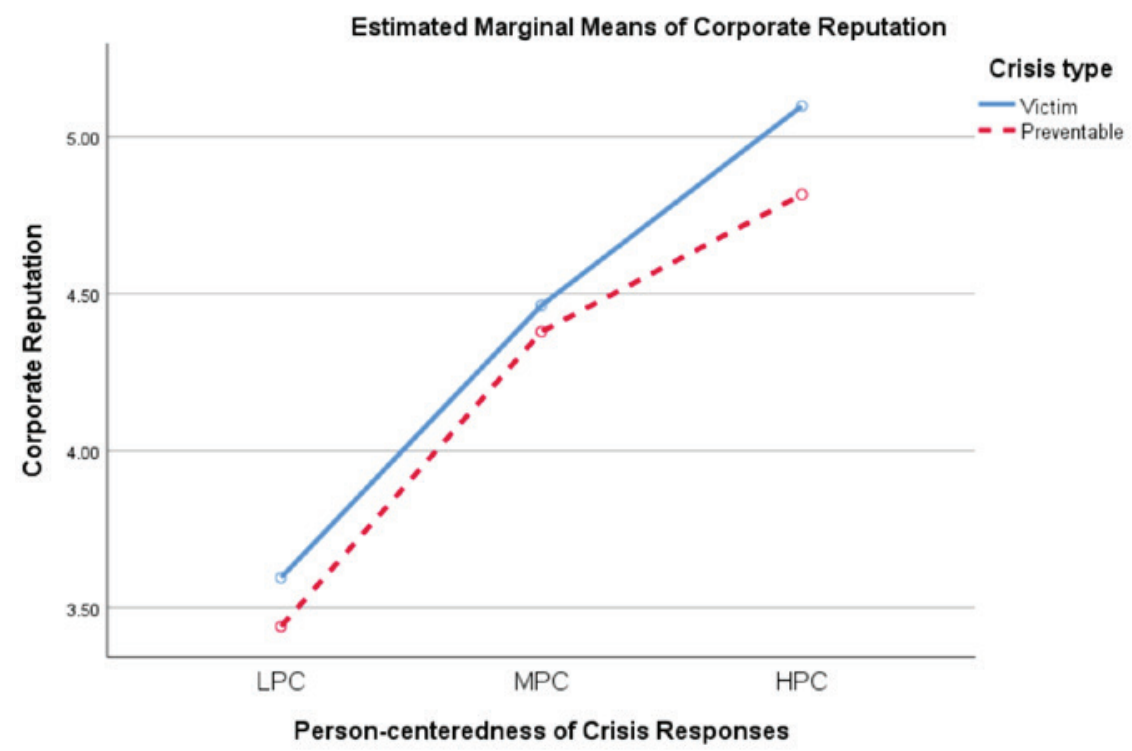




\section{Negative WOM Intention}

We examined the influence of crisis type and PCM levels on negative WOM intentions. Our findings suggest that there was a significant main effect of crisis type on negative WOM intention $(F(1$, $131)=8.66, p=.004)$. The effect size was medium $\left(\eta^{2}=.06\right.$; Cohen, 1988). Mean scores show that negative WOM intention was higher for the preventable crisis type $(M=3.59)$ than the victim $(M=$ 2.96) types. This suggests the participants were more likely to intend to share negative comments about the organization with others with increases in an organization's responsibility. Therefore, Hic was supported. A significant main effect of the PCM levels on the negative WOM intention was also found $(F(2,262)=29.25$, $p=.00)$. The eta-squared $\left(\eta^{2}\right)$ was .18, a large effect (Cohen, 1988). The mean scores indicate that people are less likely to intend to say negative things about the organization as the person-centeredness of crisis responses on social media is increased (See Table 3). Thus, H2c was also supported. No significant interaction was found $(F(2,262)=.77, p=.46)$. Figure 4 plots negative WOM intention for three levels of person-centeredness in the victim and preventable crisis types.

FIGURE 4 Negative WOM Intention for Three Levels of Person-Centered Messages in the Victim and Preventable Crisis Types

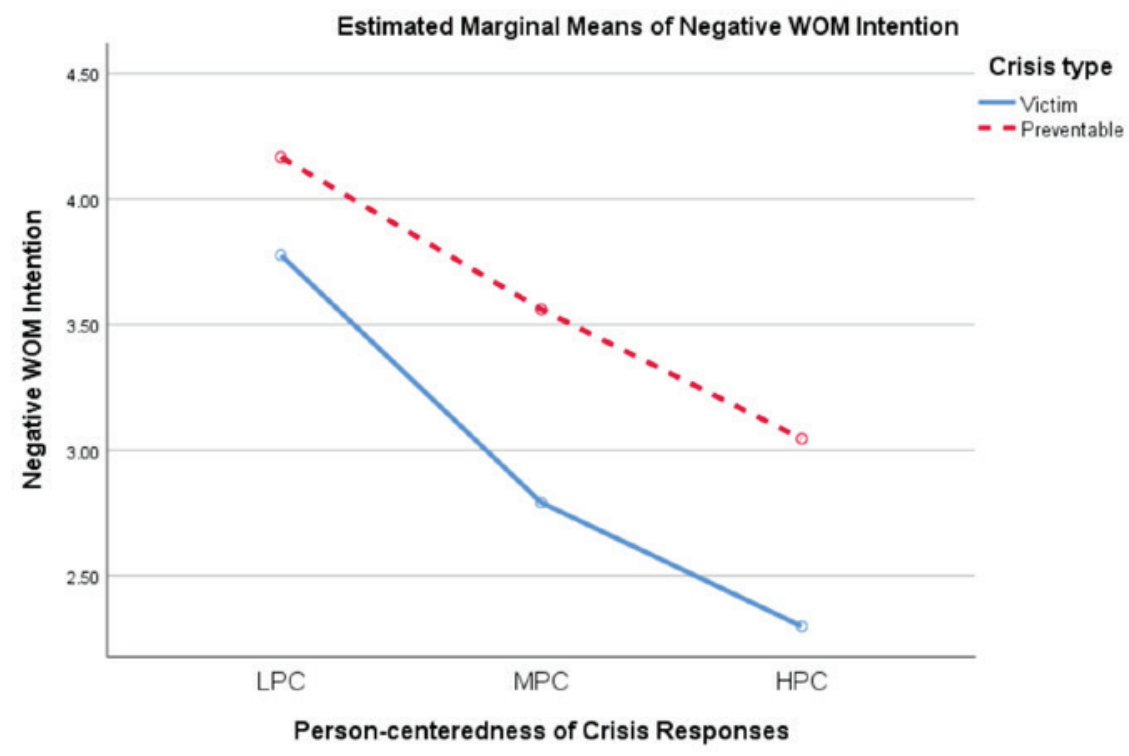




\section{Discussion}

Findings from this exploratory study shed light on crisis communication from an interdisciplinary perspective, especially regarding considerations for practice when responding to crises on social media. PCM levels in crisis response were a significant factor for participants' negative emotions, organizational reputation, and negative WOM intentions. These findings emphasize the importance of employing person-centered strategies in crisis communication on social media.

Social media offer a group of unprecedented, comprehensive communication platforms that cross between mass and personal communication. Amid platform differences, most popular social media services allow for an individual's ideas and opinions to be posted in the likes of personal communication messages, at the same time being shared with the public (Oh \& Choi, 2017; B. L. Ott, 2017). This blurring of the private and the public has been a significant topic in scholarship as of late. Dey (2020) discusses how individual voices lead to heightened levels of activism across societies. While Kruse et al. (2018) found that the younger generation refrains from actively sharing political opinions on social media, their findings indicate that social media still fosters strong engagement with like-minded individuals. And on the topic of how information originating from private spheres spread to publics, Gil de Zúñiga \& Bimber (2020) posits that social media serves as the provenance of information that shapes public discourse.

As this is the case, each user's appreciation of the corporate message ends up shaping the overall reputation of the organization. Although individual voices of concern about an organization may start at the personal level, they spread through the individual's networks and become source messages that could snowball into public perceptions. Therefore, and given how users treat social media messages with personal standards, organizations should look to formulate messages attending to the individual person.

In a meta-analysis of corporate reputation, Gatzert (2015) found that damaging events impact corporate reputation, and vice versa, which lead to negative stakeholder behavior and weakened financial performance. That is, merely focusing on normalizing 
business operations is not sufficient to overcome a crisis to the ultimate benefit of the organization.

In crisis situations, showing sympathy and remorse for the situation fosters a positive persona about the corporation. The corporate persona is important because it is the first step in public opinion formation about an organization (Charlebois \& Van Acker, 2016). At a crucial point postcrisis, the corporation's reputation isn't damaged as much when it provides personal attention, because the corporation would be construed as responsible and caring. However, if the corporation's persona is defined as culpable and negligent when its messages are not centered at the stakeholders, significant impairment in crisis recovery could occur. Interpersonal communication research suggests similar parallels when more personalized messages are shared-support recipients receiving PCM messages were likely to rate providers more favorably (L. Feng et al., 2015).

These findings are crucial for understanding how consumers' expectations for crisis communication are shifting to a new dimension with social media. Audiences on social media should be treated as any stakeholder group would. Their needs and demands should be identified and resolved, while tailoring messages to show that the organization cares for them. In so doing, PCM tactics from pertinent scholarship-namely, offering support rather than explanation, providing facilitated access to solutions, and putting the affected individual's feelings first-would be appropriate. As Fediuk et al. (2010) noted, crisis response tactics should be rooted in the goal and strategy, in that it is used to influence stakeholders' perceptions in some way. Currently, crisis communication research tends to focus on minimizing damage and protecting the organization; for crisis management on social media, we suggest that organizations should establish strategies to maintain organizational reputation after a crisis (Fediuk et al., 2010) and operationalize them through communicative tactics that integrate PCMs.

Furthermore, lower PCM levels led to stronger intentions to share negative content about the organization. This can be attributed to the current social media landscape and rising empowerment and engagement among users. Social media users display 
higher levels of attachment to various issues (Gearhart \& Zhang, 2015; B. L. Ott, 2017), making them stronger than meets-the-eye stakeholders for any crisis. When they see that an organization did not "own up" to a crisis, they will likely see this as unjust actions of businesses and display stronger levels of engagement by generating and sharing negative messages.

While Hia (negative feelings toward the organization) and $\mathrm{H} 1 \mathrm{~b}$ (corporate reputation) were not supported for differing levels of crisis, H1c (behavioral intentions) was supported. This might illustrate that online users are quick to jump to negative actions even if their perceptions toward the organization's responsibility or corporate reputation were not significantly damaged. Alternatively, this could also mean perceived reputation of the organization can still be damaged in any crisis case due to consumers' active posting and feedback (Kiambi \& Shafer, 2016).

Moreover, social media have amplified the information people receive, both in terms of sheer amount and kind. That is, users on social media are able to witness more frequently what is happening with organizations, including a variety of different activities or events. Consequently, organizations are increasingly being placed under the magnifying glass-because more such information is accessible, organizations are more prone to displaying reprehensible behavior.

For this reason, we believe users may gradually be distinguishing less what may have been distinct crisis types but are simply becoming dissatisfied with an organization. In this study, the victim situation included flight cancellations due to inclement weather; while there was not much the organization could do about it, social media users still emphasized their inconvenience over level of responsibility, thereby showing similar emotional reactions (negative) and attitudinal response (regarding the organization's reputation).

We note that participants displayed an increased willingness to engage in negative WOM in preventable crisis types. From an interpersonal communication lens, this may be explained by turning to work on action tendencies that provide insight on the connection between emotional processing and consumer behavior. According to Lazarus (1991), when individuals are angry, they 
are likely to attack those who are considered blameworthy for the offense. Even if an individual experiences negative emotions and low organization reputation in both cases, they could be triggered to share negative WOM when the responsibility (and, therefore, blame) of the organization is clearly identified. In preventable crises, stakeholders would particularly be able to identify the organization to blame, and the complaints would likely increase since the organization is an easy target (Kang et al., 2019).

Indeed, studies show that corporations' crisis responses impact consumer emotions, leading to attitudinal and/or behavioral reactions. Xiao and colleagues (2018) studied how stakeholders reacted to emotion placement in crisis response messages, finding that incorporating different emotions for different crisis types worked better for decreasing the individual's negative word-ofmouth intentions. A study on stakeholders' response to corporate social irresponsibility (CSI) found that individuals display emotional reactions (sympathy) to victims of CSI and that this leads to intentions for punitive actions toward the organization (Antonetti, 2016). Results from Ayoko and colleagues (2017) suggest that an organization's crisis response messages-especially messages communicated by managers-have a profound effect on internal stakeholders' emotions.

This highlights the need of organizations to proactively prepare for negative WOM. With the enhanced means to engage with messages and availability for one-to-many dialogue in social media communication (Gearhart \& Zhang, 2015; Grunig, 2009), this possibly means that behavioral intentions on social media emerge more quickly than ever (L. Feng et al., 2015). As Benoit (2018) also notes with the United Airlines case, this points to the growing possibility of social media backlash occurring almost simultaneously with the crisis' occurrence, making speedy crisis response a priority. As such, Brummette \& Fussell Sisco (2015) found that Twitter users tend to share emotions in their posts, thus recommending that organizations could monitor the platform to gauge public sentiments to craft better messages.

Finally, we take note that no significant interaction effects were found between crisis type and PCM levels. We argue that this is because crisis message quality is important in any crisis. In other 
words, a mere difference in crisis type does not warrant that participants will have particularly more (or less) favorable attitudes or behavioral intentions based on PCM level. Rather, our findings seem to indicate that participants overall gave more positive responses as PCM levels went up, regardless of crisis type.

\section{Conclusion and Practical Implications}

We acknowledge that this study is not without limitations, and also provide direction for future research on the topic. This study strictly focused on Twitter to better understand how users respond to messages in the social media setting; future studies comparing crisis responses on social media with other forms of online media or traditional media would help further understand the effectiveness of PCMs in various means of crisis response.

Additionally, this study collected data from college students, who are usually considered to be more homogenous than representative samples. While some researchers such as Lucas (2003) and Kardes (1996) have argued that using college students is appropriate for studies focusing on understanding basic psychological processes, several studies (i.e., Peterson \& Merunka, 2014) have noted the limitations of using convenience samples of college students, especially in generalizing the results to non-student populations. Consequently, future studies with different samples are needed to determine whether the results vary with other populations.

Our goal was to assess if crisis types and PCMs affect how participants perceive crisis response message quality and their corresponding attitudes toward the organization, which includes post-crisis organizational reputation, emotions, perceived responsibility of the organization, and behavioral intentions. We believe that this study can contribute to professional practice with its interdisciplinary approach and findings. That is, we posit that research from interpersonal communication (PCMs) can be applied to practice in a key area of $\mathrm{PR}$, crisis communication. This paper's practical implications may be summarized in three aspects: (1) evaluating the crisis; (2) communicating the crisis; and (3) crisis management on social media. 
First, evaluating the crisis refers not merely to measuring success or recovery, but assessing the crisis upon its occurrence. As soon as a crisis-like situation is monitored on social media, practitioners ought to first identify the type of crisis, assess the level of responsibility on the part of the organization, and, most importantly, ensure that the organization's assessment of responsibility recognizes social media users. As we found in this study, users are quick to make judgments based on crisis type and their motivations to share negative feedback is affected as a result. Therefore, the severity of the crisis should be considered in executing a crisis management strategy.

There is more, however: PR practitioners should also carefully examine key stakeholder groups and pinpoint their psychographics, needs, and demands. Noteworthy here is that such activities should go beyond conventional definitions of "the affected." Publics not only look at the organization's responsibility level, but how well they exercise person-centeredness in dealing with stakeholders. Therefore, conducting ample research and vetting the crisis level plus all possibly affected publics (i.e., expanding the search and research of online stakeholders) are key. This points to the ever-more importance of properly handling the proactive and strategic phases of conflict management on social media. We recommend that organizations would benefit from putting a detailed proactive crisis plan in place, perhaps designating more members of the workforce to monitor and assess crises.

Similarly, pertinent work on social media and organizational communication emphasizes the importance of listening. MacNamara (2016) notes that while the importance of listening is noted enthusiastically throughout the interpersonal literature, it is "surprisingly and problematically overlooked in . . organizational-public communication" (p. 133). Online activity has been dominated by "speaking up" (Crawford, 2009) rather than listening. Therefore, organizations should employ more canons of listening (see MacNamara, 2016), several of which reflect qualities of highly person-centered messages (e.g., giving consideration, responding, engaging in interpretation with the goal of understanding). Providing increasingly person-centered messages is one 
way in which organizations can note that they are listening to publics' concerns during times of crisis.

Second, in communicating the crisis on social media, PR professionals should rethink communicative competence in their response. Our key finding is that when engaged in crisis communication, PCM levels are a main factor in how participants respond in both their attitudes and behavioral intentions. Thus, crisis communication should be operated with a person-centered mindset, and each response should consider how the receiver would personally feel. PCM strategies such as assuming responsibility, putting the emotions of the receiver first, displaying apologetic gestures, offering support, and providing solutions should be adopted. These approaches will also be useful for image repair tactics (Gribas et al., 2018). Although we acknowledge that PCM and social support scholarship maintains all levels of PCM to be important (i.e., even LPC could be treated as a support attempt), we argue that enhancing message quality is about improving the level and skill of utilizing PCMs.

However, as Rains and colleagues (2016) note there is more development needed to explore how person-centered messages are used in computer-mediated communication (CMC) settings. As such, additional research is needed that examines how and when organizations choose to employ person-centered messages through mediated channels. While our study focused specifically on exploring three examples of crises within a hypothetical airline in social media communication, we suggest future scholarship should also explore if and how differences in person-centered messages can occur in online versus face-to-face crisis situations. Though increasing number of crises are occurring online (Coombs \& Holladay, 2012b), scholars would benefit from understanding the implications of message quality in crisis settings and the differences that exist in relation to the channel(s) in which they are provided.

A caveat for employing PCMs would be that an organization should not misunderstand person-centered messages as mere friendliness, therefore lacking professionalism. Enhancing message quality through PCMs does not necessarily mean that formal 
language and corporate-level communication should be discarded. Official statements and business communication materials should consistently adhere to showing authority and being factual. We also believe a meaningful challenge for practitioners would be to find the right balance. All in all, we still maintain that revamping the writing, editing, and reviewing process of messages with PCMs in mind will be helpful for practitioners in handling crises on social media.

Finally, we emphasize how all of this has been elevated to new dimensions in the rapidly developing digital landscape. PCMs should be considered with even more weight in crisis communication on social media because of the personal communication characteristics of social media and its users. In relation to the second aspect above, we might also add that social media serve as a useful channel for person-centered communication efforts since consumers feel at ease on social media-arguably, practitioners would be reaching out to stakeholders on their own turf, thereby enhancing the effectiveness of messages. Furthermore, we believe that existing thoughts on crisis types may need to be revisited, since accidental type crises were perceived just as crucial as preventable crises in the social media setting. Therefore, crisis threats (called "paracrisis" by Coombs \& Holladay, 2012b, p. 408) online requires practitioners to take a more cautionary approach. Also, every organization should be prepared for social media backlash, big and small, and be ready to engage in two-way communication with stakeholders. This calls for the necessity of designated social media teams who are capable of proper research and incorporating quality in PCM in the writing, disseminating, and evaluating social media communication.

\section{References}

Abendschein, B. (2020). Uncertainly management in online support forums for stroke survivors and caregivers. In N. Egbert \& K. B. Wright (Eds.), Social support and health in the digital age (pp. 149-170): Lexington. 
Antonetti, P. (2016). Social identification and corporate irresponsibility: A model of stakeholder punitive intentions. British Journal of Management, 27(3), 583-605. https://doi. org/10.1111/1467-8551.12168

Ayoko, O. B., Ang, A. A., \& Parry, K. (2017). Organizational crisis: Emotions and contradictions in managing internal stakeholders. International Journal of Conflict Management, 28(5), 617-643. https://doi.org/10.1108/IJCMA-05-2016-0039

Benoit, W. L. (2018). Crisis and damage repair at United Airlines: Fly the unfriendly skies. Journal of International Crisis \& Risk Communication, 1(1), 11-26. https://doi.org/10.30658/ jicrcr.1.1.2

Bergkvist, L., \& Rossiter, J. R. (2007). The predictive validity of multiple-item versus single-item measures of the same constructs. Journal of Marketing Research, 44(2), 175-184. https:// doi.org/10.1509/jmkr.44.2.175

Bodie, G. D., \& Jones, S. M. (2016). Constructivism. In C. R. Berger \& M. E. Roloff (Eds.), The International Encyclopedia of Interpersonal Communication. Wiley.

Brummette, J., \& Fussell Sisco, H. (2015). Using Twitter as a means of coping with emotions and uncontrollable crises. Public Relations Review, 41(1), 89-96. https://doi.org/10.1016/j. pubrev.2014.10.009

Burleson, B. R. (1982). The development of comforting communication skills in childhood and adolescence. Child Development, 51, 1578-1588. https://doi.org/10.2307/1130086

Burleson, B. R. (1987). Cognitive complexity. In J. C. McCroskey \& J. A. Daly (Eds.), Personality and Interpersonal Communication (pp. 3-28). Sage.

Burleson, B. R. (1994). Comforting messages: Features, functions, and outcomes. In J. A. Daly \& J. M. Wiemann (Eds.), Strategic Interpersonal Communication (pp. 135-161). Earlbaum.

Burleson, B. R. (2008). What counts as effective emotional support? Explorations of situational and individual differences. In M. T. Motley (Ed.), Studies in Applied Interpersonal Communication (pp. 207-227). Sage. 
Charlebois, S., \& Van Acker, R. (2016). In the belly of the "beast": A look at Monsanto's public engagement awakening. Public Relations Review, 42(1), 223-225.

Cohen, J. (1988). Statistical power analysis for the behavioral cciences. Routledge.

Coombs, W. T. (2007). Protecting organization reputations during a crisis: The development and application of situational crisis communication theory. Corporate Reputation Review, 1o(3), 163-176. https://doi.org/10.1057/palgrave.crr.1550049

Coombs, W. T. (2011). Ongoing crisis communication: Planning, managing, and responding. Sage.

Coombs, W. T., \& Holladay, S. J. (2002). Helping crisis managers protect reputational assets: Initial tests of the situational crisis communication theory. Management Communication Quarterly, 16, 165-186. https://doi.org/10.1177/089331802237233

Coombs, W. T., \& Holladay, S. J. (2004). Reasoned action in crisis communication: An attribution-theory based approach to crisis management. In D. P. Millar \& R. L. Heath (Eds.), Responding to Crisis: A Rhetorical Approach to Crisis Communication (pp. 95-115). Routledge.

Coombs, W. T., \& Holladay, S. J. (2005). An exploratory study of stakeholder emotions: Affect and crises. In N. M. Ashkanasay, W. J. Zerbe, \& C. E. J. Hartel (Eds.), The Effect of Affect in Organizational Settings (pp. 263-280). Emerald.

Coombs, W. T., \& Holladay, S. J. (2008). Comparing apology to equivalent crisis response strategies: Clarifying apology's role and value in crisis communication. Public Relations Review, 34, 252-257. https://doi.org/10.1016/j.pubrev.2008.04.001

Coombs, W. T., \& Holladay, S. J. (2009). Further explorations of post-crisis communication: Effects of media and response strategies on perceptions and intentions. Public Relations Review, 35(1), 1-6. https://doi.org/10.1016/j.pubrev.2008.09.011

Coombs, W. T., \& Holladay, S. J. (2012a). Amazon.com's Orwellian nightmare: Exploring apology in an online environment. Journal of Communication Management, 16(3), 280-295. https://doi.org/10.1108/13632541211245758 
Coombs, W. T., \& Holladay, S. J. (2012b). The paracrisis: The challenges created by publicly managing crisis prevention. Public Relations Review, 38(3), 408-415. https://doi.org/10.1016/j. pubrev.2012.04.004

Crawford, K. (2009). Following you: Disciplines of listening in social media. Continuum: Journal of Media \& Cultural Studies, 23(4), 525-535. https://doi.org/10.1080/10304310903003270

Czepiel, J. A., Solomon, M. R., Surprenant, C. F., \& Gutman, E. G. (1985). Service encounters: An overview. In J. A. Czepiel \& M. R. Solomon (Eds.), The Service Encounter: Managing Employee/Consumer Interaction in Service Businesses (pp. 3-16). Lexington.

Delia, J. G., O’Keefe, B. J., \& O’Keefe, D. J. (1982). The contructivist approach to communication. In F. E. X. Dance (Ed.), Human Communication Theory: Comparative Essays (pp. 147-191). Harper \& Row.

De Waele, A., Schoofs, L., \& Claeys, A.-S. (2020). The power of empathy: The dual impacts of an emotional voice in organizational crisis communication. Journal of Applied Communication Research, 48(3), 350-371. https://doi.org/10.1080/00909882.2 020.1750669

Dey, S. (2020). Let there be clamor: Exploring the emergence of a new public sphere in India and use of social media as an instrument of activism. Journal of Communication Inquiry, 44(1), 48-68. https://doi.org/10.1177/0196859919827319

Diddi, P., \& Lundy, L. K. (2017). Organizational Twitter use: Content analysis of tweets during breast cancer awareness month. Journal of Health Communication, 22(3), 243-253. https://doi.org/10.1080/10810730.2016.1266716

Dotchin, J. A., \& Oakland, J. S. (1994). Total quality management in services: Part 1: Understanding and classifying services. International Journal of Quality \& Reliability Management, 11(3), 9-26. https://doi.org/10.1108/02656719410056459

Edvardsson, B. (1992). Service breakdowns: A study of critical incidents in an airline. International Journal of Service Industry Management, 3(4), 309-327. https://doi. org/10.1108/09564239210019450 
Eichhorn, K. C. (2008). Soliciting and providing social support over the internet: An investigation of online eating disorder support groups. Journal of Computer-Mediated Communication, 14, 67-78. https://doi.org/10.1111/j.1083-6101.2008.01431.x

Eriksson, M. (2012). On-line strategic crisis communication: In search of descriptive model approach. International Journal of Strategic Communication, 6(4), 309-327. https://doi.org/10.10 80/1553118x.2012.711403

Fediuk, T. A., Pace, K. M., \& Botero, I. C. (2010). Crisis response effectiveness: Methodological considerations for advancement in empirical investigation into response impact. In W. T. Coombs \& S. J. Holladay (Eds.), The Handbook of Crisis Communiation (pp. 221-242). Blackwell.

Feng, B., Li, S., \& Li, N. (2016). Is a profile worth a thousand words? How online support-seeker's profile features may influence the quality of received support messages. Communication Research, 43(2), 253-276. https://doi.org/10.1177/0093650213510942

Feng, L., Hu, Y., Li, B., Stanley, E., Havlin, S., \& Braunstein, L. A. (2015). Competing for attention in social media under information overload conditions. PLOS One, 10(7), e0126090. https://doi.org/10.1371/journal.pone.0126090

Gatzert, N. (2015). The impact of corporate reputation and reputation damaging events on financial performance: Empirical evidence from the literature. European Management Journal, 33(6), 486-499. https://doi.org/10.1016/j.emj.2015.10.001

Gearhart, S., \& Zhang, W. (2015). "Was it something I said?" "No, it was something you posted!" A study of the spiral of silence theory in social media contexts. Cyberpsychology, Behavior, and Social Networking, 18(4), 208-213. https://doi.org/10.1089/ cyber.2014.0443

Gil de Zúñiga, H., \& Bimber, B. (2020). The unedited public sphere. New Media \& Society, 22(4), 700-715. https://doi. org/10.1177/1461444819893980

Gliner, J. A., Morgan, G. A., \& Leech, N. L. (2009). An integrated approach to design and analysis (2nd ed.). Routledge. 
Goldstein, M. (2017, December 20). Biggest travel story of 2017: The bumping and beating of Dr. David Dao. Forbes. https:// web.archive.org/web/20171222064041/https://www.forbes. $\mathrm{com} /$ sites/michaelgoldstein/2017/12/20/biggest-travel-storyof-2017-the-bumping-and-beating-of-doctor-david-dao/

Gribas, J., Disanza, J., Legge, N., \& Hartman, K. L. (2018). Organizational image repair tactics and crisis type: Implications of crisis response strategy effectiveness. Journal of International Crisis \& Risk Communication, 1(2), 225-252. https://doi. org/10.30658/jicrcr.1.2.3

Grunig, J. (2009). Paradigms of global public relations in an age of digitalization. PRism, 6(2), 1-19.

Hauser, C. (2018, November 2). 'Are you actually an M.D.?': A black doctor is questioned as she intervenes on a Delta flight. The New York Times. https://www.nytimes.com/2018/11/02/ us/delta-black-doctor-racial-profiling.html

High, A. C., \& Dillard, J. P. (2012). A review and meta-analysis of person-centered messages. Communication Studies, 63(1), 99-118. https://doi.org/10.1080/10510974.2011.598208

Hong, S., \& Len-Riós, M. E. (2015). Does race matter? Implicit and explicit measures of the effect of the PR spokesman's race on evaluations of spokesman source credibility and perceptions of a PR crisis' severity. Journal of Public Relations Research, 27, 63-80. https://doi.org/10.1080/1062726x.2014.929502

Jiang, H., Luo, Y., \& Kulemeka, O. (2016). Social media engagement as an evaluation barometer: Insights from communication executives. Public Relations Review, 42(4), 679-691. https://doi.org/10.1016/j.pubrev.2015.12.004

Jin, Y. (2009). The effects of public's cognitive appraisal of emotions in crises on crisis coping and strategy assessment. Public Relations Review, 35(2009), 310-313. https://doi.org/10.1016/j. pubrev.2009.02.003

Jones, S. (2004). Putting the person in person-centered and immediate emotional support, emotional change and perceived helper competence as outcomes of comforting in helping situations. Communication Research, 31(3), 338-36o. https://doi. org/10.1177/0093650204263436 
Jones, S., \& Bodie, G. (2014). Supportive communication. In C. R. Berger (Ed.), Interpersonal Communication (Vol. 6, pp. 371394). Berlin, Germany: De Gruyter Mouton.

Jong, W., \& Dückers, M. L. (2016). Self-correcting mechamisms and echo-effects in social media: An analysis of the "gunman in the newsroom" crisis. Computers in Human Behavior, 59, 334-341. https://doi.org/10.1016/j.chb.2016.02.032

Jorgensen, B. K. (1996). Components of consumer reaction to company-related mishaps: A structural equation model approach. Advances in Consumer Research, 23, 346-351.

Kang, S., Shim, K., \& Kim, J. (2019). Social media posts on Samsung Galaxy Note 7 explosion: A comparative analysis of crisis framing and sentiments in three nations. Journal of International Crisis \& Risk Communication, 2(2), 259-290. https://doi.org/10.30658/jicrcr.2.2.5

Kardes, F. R. (1996). In defense of experimental consumer pyschology. Journal of Consumer Psychology, 5(3), 279-296. https:// doi.org/10.1207/s15327663jcp0503_04

Kiambi, D. M., \& Shafer, A. (2016). Corporate crisis communication: Examining the interplay of reputation and crisis response strategies. Mass Communication and Society, 19(2), 127-148. https://doi.org/10.1080/15205436.2015.1066013

Killian, G., \& McManus, K. (2015). A marketing communications approach for the digital era: Managerial guidelines for social media integration. Business Horizons, 58(5), 539-549. https:// doi.org/10.1016/j.bushor.2015.05.006

Kim, J., \& Jin, Y. (2016). Understanding emotionally involved publics: The effects of crisis type and felt involvement on publics' emotional responses to different consumer product crises. Corporate Communications, 21(4), 465-482. https://doi. org/10.1108/CCIJ-10-2015-0064

Kim, S., \& Sung, K. H. (2014). Revisiting the effectiveness of base crisis response strategies in comparison of reputation management crisis responses. Journal of Public Relations Research, 26(1), 62-78. https://doi.org/10.1080/1062726x.2013.795867 
Kruse, L. M., Norris, D. R., \& Filinchum, J. R. (2018). Social media as a public sphere? Politics on social media. The Sociological Quarterly, 59(1), 62-84. https://doi.org/10.1080/00380253.20 17.1383143

Lambdin, C., \& Shaffer, V. A. (2009). Are within-subjects design transparent? Judgment and Decision Making, 4(7), 554-566. http://journal.sjdm.org/9921/jdm9921.pdf

Lazarus, R. S. (1991). Emotion and adaptation. Oxford University Press.

Lee, S. L., Kim, J., Golden, K. J., Kim, J. H., \& Park, M. S. A. (2016). A cross-cultural examination of SNS usage intensity and managing interpersonal relationships online: The role of culture and the autonomous-related self-construal. Frontiers in Psychology, 7, 376. https://doi.org/10.3389/fpsyg.2016.00376

Lucas, J. W. (2003). Theory-testing, generalization, and the problem of external validity. Sociological Theory, 21(3), 236-253. https://doi.org/10.1111/1467-9558.00187

Lyon, L., \& Cameron, G. T. (2004). A relational approach examining the interplay of prior reputation and immediate response to a crisis. Journal of Public Relations Research, 16(3), 213-241. https://doi.org/10.1080/1532-754X.2004.11925128

MacNamara, J. (2016). The work and 'architecture of listening': Addressing gaps in organization-public communication. International Journal of Strategic Communication, 10(2), 133148. https://doi.org/10.1080/1553118x.2016.1147043

Matousek, M. (2018, April 18). Passenger killed in Southwest engine explosion was partially sucked out of plane's broken window. Business Insider. https://web.archive.org/ web/20180418180340/https://www.businessinsider.com/ southwest-passenger-torso-sucked-out-window-after-engineexplosion-2018-4

Oh, S., \& Choi. H. (2017). Broadcasting upon a shooting star: Investigating the success of Afreeca TV's livestream personal broadcast model. International Journal of Web Based Communities, 13(2), 193-212. https://doi.org/10.1504/IJWBC. 2017.10004114 
Ott, B. L. (2017). The age of Twitter: Donald J. Trump and the politics of debasement. Critical Studies in Media Communication, 34(1), 59-68. https://doi.org/10.1080/15295036.2016.1266686 Pace, S., Balboni, B., \& Gistri, G. (2017). The effects of social media on brand attitude and WOM during a brand crisis: Evidences from the Barilla case. Journal of Marketing Communications, 23(2), 135-148. https://doi.org/10.1080/13527266.2014.9664 78

Pan, W., Feng, B., \& Li, S. (2020). Online support groups dedicated to specific health problems. In N. Egbert \& K. B. Wright (Eds.), Social support and health in the digital age (pp. 109128): Lexington.

Peterson, R. A., \& Merunka, D. R. (2014). Convenience samples of college students and research reproducibility. Journal of Business Research, 67(5), 1035-1041. https://doi.org/10.1016/j. jbusres.2013.08.010

Pfeffer, J., Zorbach, T., \& Carley, K. M. (2014). Understanding online firestorms: Negative word-of-mouth dynamics in social media networks. Journal of Marketing Communications, 2o(1/2), 117-128. https://doi.org/10.1080/13527266.2013.797 778

Ponzi, L. J., Fombrun, C. J., \& Gardberg, N. A. (2011). RepTrak Pulse: Conceptualizing and validating a short-form measure of corporate reputation. Corporate Reputation Review, 14(1), 15-35. https://doi.org/10.1057/crr.2011.5

Rains, S. A., Brunner, S. R., Akers, C., Pavlich, C. A., \& Tsetsi, E. (2016). The implications of computer-mediated communication (CMC) for social support message processing and outcomes: When and why are the effects of support messages strengthened during CMC? Human Communication Research, 42, 533-576. https://doi.org/10.1111/hcre.12087

Rosenberg, E. (2017, April 22). American Airlines suspends flight attendant after altercation over stroller. The New York Times. https://web.archive.org/web/20170422215557/https://www. nytimes.com/2017/04/22/business/american-airlines-videostroller.html 
Schoofs, L., Claeys, A.-S., De Waele, A., \& Cauberghe, V. (2019). The role of empathy in crisis communication: Providing a deeper understanding of how organizational crises and crisis communicatino affect reputation. Public Relations Review, 45(5), 101851. https://doi.org/10.1016/j.pubrev.2019.101851

Schultz, F., Utz, S., \& Göritz, A. (2014). Is the medium the message? Perceptions of and reactions to crisis communication via Twitter, blogs and traditional media. Public Relations Review, 37(1), 20-27. https://doi.org/10.1016/j.pubrev.2010.12.001

Sellnow, D. D., Lane, D., Littlefield, R. S., Sellnow, T. L., Wilson, B., Beauchamp, K., \& Venette, S. (2015). A receiver-based approach to effective instructional crisis communication. Journal of Contingencies \& Crisis Management, 23(3), 149-158. https://doi.org/10.1111/1468-5973.12066

Smith, D. (2005). Business (not) As usual: Crisis management, service recovery and the vulnerability of organisations. Journal of Service Marketing, 19(5), 309-320. https://doi. org/10.1108/08876040510609925

Veil, S. R., Beuhner, T., \& Palenchar, M. J. (2011). A work-in process literature review: Incorporating social media in risk and crisis communication. Journal of Contingencies \& Crisis Management, 19(2), 110-122. https://doi.org/10.1111/j.14685973.2011.00639.X

Wright, K., Rosenberg, J., Egbert, N., Ploeger, N., Bernard, D., \& King, S. (2012). Communication competence, social support, and depression among college students: A model of Facebook and face-to-face support network influence. Journal of Health Communication, 18(1), 41-57. http://doi.org/10.1080/108107 30.2012.688250

Xiao, Y., Hudders, L., Claeys, A.-S., \& Cauberghe, V. (2018). The impact of expressing mixed valence emotions in organizational crisis communication on consumer's negative word-of-mouth intention. Public Relations Review, 44(5), 794-806. https://doi. org/10.1016/j.pubrev.2018.10.007 
Zhao, X., Zhan, M. M., \& Liu, B. F. (2019). Understanding motivated publics during disasters: Examining message functions, frames, and styles of social media influentials and followers. Journal of Contingencies \& Crisis Management, 27(4), 387-399. https://doi.org/10.1111/1468-5973.12279

Zhao, X., Zhan, M. M., \& Ma, L. (2020). How publics react to situational and renewing organizational responses across crises: Examining SCCT and DOR in social-mediated crises. Public Relations Review, 46(4), 101944. https://doi.org/10.1016/j. pubrev.2020.101944 